\title{
Relationship Between Mental Fatigue and Mental Workload Among
}

\section{Nurses}

\author{
Ehsan Bakhshi (iD) ${ }^{1}$, Adel Mazloumi ${ }^{2,3,{ }^{*}}$ and Seyed Mostafa Hoseini ${ }^{4}$ \\ ${ }^{1}$ Islamabad-e-Gharb Health Care Network, Kermanshah University of Medical Sciences, Kermanshah, Iran \\ ${ }^{2}$ Department of Occupational Health Engineering, School of Public Health, Tehran University of Medical Sciences, Tehran, Iran \\ ${ }^{3}$ Sports Medicine Research Center, Neuroscience Institute, Tehran University of Medical Sciences, Tehran, Iran \\ ${ }^{4}$ Department of Epidemiology and Biostatistics, School of Public Health, Tehran University of Medical Sciences, Tehran, Iran \\ Corresponding author: Associate Professor, Department of Occupational Health Engineering, School of Public Health, Tehran University of Medical Sciences, Tehran, Iran. \\ Email:amazlomi@tums.ac.ir
}

Received 2018 August 08; Revised 2018 November 06; Accepted 2019 January 12.

\begin{abstract}
Background: Mental fatigue is a very common problem in everyday modern life, during which, individual performance decreases for complex cognitive activities.

Objectives: This study aimed to determine the level of mental fatigue and its relationship with mental workload among nurses. Methods: In this descriptive analytical cross-sectional study, 203 nurses were selected from several hospital wards in Kermanshah, Iran. A demographic form, Mental Fatigue Scale (MFS) and NASA-TLX were used to obtain data. The data were analyzed by Pearson correlation coefficient, analysis of variance and independent $t$-test.

Results: The mean (SD) scores for the participants' mental fatigue and mental workload were 13.24 (7.41) and 69.73 (15.26), respectively. Data analysis did not show any significant relationship between mental fatigue and mental workload $(\mathrm{P}=0.120)$.

Conclusions: Generally, most of the nurses perceived having minor problems to no problems with respect to mental fatigue, and workload was not found as a contributing factor to mental fatigue.
\end{abstract}

Keywords: Mental Fatigue, Mental Workload, Hospital, Nurses, NASA-TLX

\section{Background}

Nurses are the largest group working in the health care system constituting roughly $40 \%$ of all employees per hospitals and 55\% of the total employee expenses. Therefore, they have an important role in the health care system (1). Nurses often encounter stressful and emotional situations, such as patients' death. In addition, the need for the delivery of high-quality care to higher-risk patients makes the workload increasingly challenging(2). Today, high levels of fatigue are reported in nurses, who affect patient care outcomes and imposes huge costs on the health care system (3). Fatigue has been reported among $91.9 \%$ of nurses, and according to the findings of a previous study conducted by Raftopoulos et al. (4), two-thirds of nurses experience fatigue. Work-related fatigue is an important issue that affects nurses' performance and appears as physical and mental fatigue (5). Mental fatigue is a psychobiology state caused by prolonged intense mental activity and is typically accompanied by subjective feelings of tiredness, declined mental alertness, as well as lack of energy; which compromises performance. $(6,7)$.
Based on previous research, increased level of fatigue, especially mental fatigue, is associated with decentralization and the occurrence of more errors (8). Suffering from mental fatigue, individuals can perform simple cognitive tasks, but their performance in complex mental tasks may be reduced. A possible reason for this issue is the impact of mental fatigue on information processing (9). Fatigue lowers nurses' decision-making power, increases reaction time and disturbs problem-solving ability, leading to increased errors (10). Nurses' fatigue may put patient safety and health at risk, increase the likelihood of the occurrence of adverse events and threaten nurses' health. The American Nurses Association has proven the effect of workrelated fatigue on job satisfaction (11).

Heavy workload and long working hours are key factors in the generation of fatigue (12). Besides high physical demands of nursing work, mental demands constitute an important part of the overall workload of this occupational group (13). The overall concept of workload originates from the area of human factors and is essentially related to individuals' mental abilities that is how informa- 
tion is received and processed and ultimately leads to decisions and actions. Regarding nursing work, to achieve safety, health, comfort and efficiency in the long run, a reasonable goal would be arranging the labor needs in such a way that neither extra workload nor less than necessary workload is given to nurses (14).

Exposure to prolonged stress is the most common cause of fatigue among health care workers (15). Various studies have shown that workload is one of the most important causes of occupational stress in intensive care units (16). Increased workload results in higher job pressure, occupational injury and reduced decision-making power and, thereby, it produces stress and burnout among nurses (17). Different studies have shown that people's efficiency declines in jobs with high mental workload due to fatigue and inappropriate schedule, causing memory dysfunction, damaged thinking process, irritability and decreased learning (18).

\section{Objectives}

Considering nurses' mental fatigue explained earlier, factors causing mental fatigue can be determined and controlled. Therefore, the aim of this study was to examine the possible influences of workload on mental fatigue and its relationship with demographic factors. Mental fatigue among hospital nurses has not been investigated before in Kermanshah city, Iran. The assessment of mental fatigue and interventions for controlling mental fatigue among health care workers will lead to appropriate patient safety on the one hand, and energetic and healthy nurses on the other.

\section{Methods}

\subsection{Type of Study}

This was a cross-sectional descriptive analytical study.

\subsection{The Assessment Tools}

In this study, three questionnaires were employed as follows.

\subsubsection{Demographic and General Questionnaire}

This tool includes items on age, gender, marital status, working pattern, number of shifts per month, history of employment, drug use, educational level, type of employment, body mass index (BMI) and smoking status.

\subsubsection{Mental Fatigue Scale (MFS)}

MFS motivated by Rodholm's questionnaire was designed by Johnson and Starmark in the Department of Clinical Neuroscience and Rehabilitation, Institute of Neuroscience and Physiology, the Sahlgrenska Academy, University of Gothenburg, Sweden in 2010. So far, this questionnaire has been used among cerebrovascular accident (CVA) patients, multiple sclerosis patients, traumatic brain patients, people exposed to stress and burnout sufferers. The scale includes 15 different items on fatigue, lack of initiative, mental fatigue, mental recovery, concentration difficulties, memory problems, slowness of thinking, sensitivity to stress, increased tendency to become emotional, irritability or "a short fuse", sensitivity to light, sensitivity to noise, decreased sleep at night, increased sleep and 24-hour variations (i.e., when the rate of mental fatigue is higher or lower during the day and at night) (19).

This questionnaire assesses the general state of individuals over one month and can be used in various occupational groups. In the present study, the questionnaire was first translated into Persian and then it was back translated into English. Finally, the original and back-translated versions were evaluated by an English language expert and the translated version was used after being approved.

Test-retest reliability method was used to assess the reliability of the scale. For this purpose, the questionnaire was first distributed among 15 nurses and redistributed at a 15-day interval. The possible scores range from 0 to 44 , with scores lower than 7.49 indicating no problem, 7.5 to 22.49 minor problems, 22.5 to 37.45 relatively serious problems and 37.5 to 44 serious problems. In terms of the item "24-hour variations", the score range is from 0 to 2, while it is from 3 to 3 for the other items. The two sets of scores were compared using Pearson's correlation coefficient. The testretest reliability was calculated at 0.727 at the significance level of 0.002 and Cronbach's alpha coefficient was estimated to be 0.893 .

\subsubsection{NASA Task Load Index}

NASA-TLX is one of the well-known tools for the assessment of workload from individuals' view. It is a multidimensional tool developed by Hart and Staveland in 1988 that provides an overall score of mental workload based on a weighted average of six subscales, namely mental demand, physical demand, temporal demand, effort, perceived performance and frustration. Several studies have confirmed the reliability and validity of this scale for the assessment of workload. The reliability and validity of this scale were confirmed in Iran by Mohammadi et al. (18). The possible scores range from 0 to 100 . 


\subsection{Settings and Participants}

The sample was 203 subjects at the confidence level of $95 \%$, with the statistical power of $95 \%$, and the absolute error of $25 \%$. In this study, the nurses were selected from an emergency department $(\mathrm{n}=55)$, intensive care unit $(\mathrm{n}=$ $42)$, pediatric ward (22), surgical ward $(n=44)$ and internal medicine ward $(n=40)$ at Imam Reza Hospital of Kermanshah, Iran.

\subsection{Sampling Method}

The number of samples was estimated with the significance level of $95 \%$ and error of $25 \%$. Thus, 203 employees were selected based on random sampling from the surgical ward, emergency department, pediatric ward, internal medicine ward and intensive care unit of the mentioned hospital.

\subsection{Data Collection}

To collect the required data, first a written permission was obtained from the respective authorities, then the researchers presented to the intended units at the aforementioned hospital during shifts. Then, they provided the nurses the required information and the questionnaire if they were willing to participate in the study. The participants were trained to report their status within a month then they responded to the questionnaires during shifts (beginning, middle or end of shifts).

\subsection{Statistical Analysis}

$T$-test, one-way analysis of variance (ANOVA) and Pearson correlation coefficient were run in the SPSS version 19.

\section{Results}

According to the obtained results, $73.4 \%$ of the participants were female; and $88.12 \%$ of them held a Bachelor's degree and the rest held a Master's degree. In terms of the shift type, $83.7 \%$ of the participants had varied shifts. In addition, $57.6 \%$ of the nurses were married. Only $6 \%$ of the participants had taken psychiatric medications over the past month and $97.5 \%$ of the participants had not experienced smoking. Demographic and underlying information of the nurses is shown in Table 1.

\subsection{Mental Fatigue and Mental Workload}

Regarding the results of the mental fatigue scale, the component of fatigue showed the highest score (mean: 1.39) and the component of 24-hour variations obtained the lowest score (mean: 0.42). The component of mental recovery with the mean score and standard deviation of 1.14 (0.95) and the component of sensitivity to stress with

\begin{tabular}{|c|c|c|}
\hline Variable & Frequency & Percentage \\
\hline \multicolumn{3}{|l|}{ Gender } \\
\hline Male & 54 & 26.6 \\
\hline Female & 149 & 73.4 \\
\hline \multicolumn{3}{|l|}{ Marital status } \\
\hline Single & 86 & 42.4 \\
\hline Married & 117 & 57.6 \\
\hline \multicolumn{3}{|l|}{ Drug use } \\
\hline Yes & 13 & 6.40 \\
\hline No & 190 & 93.60 \\
\hline \multicolumn{3}{|l|}{ Cigarette smoking } \\
\hline Yes & 11 & 5.41 \\
\hline No & 192 & 94.59 \\
\hline \multicolumn{3}{|l|}{ Education } \\
\hline Bachelor & 178 & 87.68 \\
\hline Master & 25 & 12.31 \\
\hline \multicolumn{3}{|l|}{ Working pattern } \\
\hline Fixed & 31 & 15.25 \\
\hline variable & 172 & 84.75 \\
\hline \multicolumn{3}{|l|}{ History of employment, $y$} \\
\hline $1-10$ & 131 & 64.53 \\
\hline $11-20$ & 58 & 28.57 \\
\hline $21-30$ & 14 & 6.9 \\
\hline \multicolumn{3}{|l|}{ Type of employment } \\
\hline Contractual & 70 & 34.5 \\
\hline Employment contract & 95 & 46.8 \\
\hline Permanent & 38 & 18.7 \\
\hline
\end{tabular}

the mean and standard deviation of $1.02(0.86)$ had higher scores than the other components.

The overall mean score of mental fatigue was equal to 13.24 (7.41), which are lower than the average value. The range of scores in this questionnaire is from 0 to 44 and the average score is 22 . The results of workload assessment showed the component of effort with the mean score and standard deviation of 70.96 and 23.15 had the highest score and the component of frustration level with the mean score and standard deviation of 44.91 and 28 had the lowest score in this study. In total, the dimensions of frustration, performance, mental demand, physical demand, temporal demand and effort had the lowest to highest scores, respectively (Table 2 ).

The highest and lowest mental fatigue scores were obtained in the emergency department and surgical ward 


\begin{tabular}{|c|c|c|}
\hline Dimensions & Mean $\pm S D$ & Range of Score \\
\hline \multicolumn{3}{|l|}{ Dimensions of mental fatigue } \\
\hline Fatigue & $1.39 \pm 0.75$ & $0-3$ \\
\hline Lack of initiative & $0.85 \pm 0.70$ & $0-3$ \\
\hline Mental fatigue & $0.83 \pm 0.81$ & $0-3$ \\
\hline Mental fatigue recovery & $1.14 \pm 0.95$ & $0-3$ \\
\hline Concentration difficulties & $0.93 \pm 0.71$ & $0-3$ \\
\hline Memory problems & $0.77 \pm 0.71$ & $0-3$ \\
\hline Slowness of thinking & $0.74 \pm 0.76$ & $0-3$ \\
\hline Sensitivity to stress & $1.02 \pm 0.86$ & $0-3$ \\
\hline $\begin{array}{l}\text { Increased tendency to become } \\
\text { emotional }\end{array}$ & $0.86 \pm 0.84$ & $0-3$ \\
\hline Irritability & $0.94 \pm 0.83$ & $0-3$ \\
\hline Sensitivity to light & $0.75 \pm 0.70$ & $0-3$ \\
\hline Sensitivity to noise & $0.91 \pm 0.72$ & $0-3$ \\
\hline Decreased sleep at night & $0.96 \pm 0.88$ & $0-3$ \\
\hline Increased sleep & $0.63 \pm 0.85$ & $0-3$ \\
\hline 24-hour variations & $0.42 \pm 0.27$ & $0-2$ \\
\hline Mental Fatigue Scale & $13.24 \pm 7.21$ & $0-44$ \\
\hline \multicolumn{3}{|l|}{ Dimensions of mental workload } \\
\hline Mental demand & $61.67 \pm 25.36$ & $0-100$ \\
\hline Physical demand & $62.35 \pm 27.22$ & $0-100$ \\
\hline Temporal demand & $63.63 \pm 26.50$ & $0-100$ \\
\hline Effort & $70.96 \pm 23.15$ & $0-100$ \\
\hline Perceived performance & $59.86 \pm 25.35$ & $0-100$ \\
\hline Frustration & $44.93 \pm 28$ & $0-100$ \\
\hline Mental Workload & $69.73 \pm 15.26$ & $0-100$ \\
\hline
\end{tabular}

with the mean (SD) of 14.55 (6.46) and 11.66 (6.22), respectively. The highest mental fatigue score belonged to the intensive care unit with the mean and standard deviation of 75.26 and 12.52, whereas the internal medicine unit with the mean and standard deviation of 59.57 and 16.38 had a lower mental workload than the other units being investigated (Table 3).

\subsection{Relationship Between Mental Fatigue and Mental Work- load}

Pearson correlation coefficient was used to assess the relationship between the components of workload and mental fatigue. The results indicated that mental fatigue was significantly correlated with frustration $(P=0.00)$, whereas the other components had no significant correlation with mental fatigue $(\mathrm{P} \leq 0.05)$. In terms of the re-

\begin{tabular}{|c|c|c|c|}
\hline Unit & Mental Workload & \multicolumn{2}{|c|}{ Mental Fatigue } \\
\hline Emergency department $(\mathrm{N}=55)$ & $70.75(13.33)$ & \multicolumn{2}{|c|}{$14.55(6.44)$} \\
\hline Intensive care unit $(\mathrm{N}=\mathbf{4 2}$ ) & $75.26(12.52)$ & \multicolumn{2}{|c|}{$12.6(8.7)$} \\
\hline Internal medicine ward $(\mathrm{N}=40)$ & $59.57(16.38)$ & \multicolumn{2}{|c|}{$13.15(6.22)$} \\
\hline Surgical ward $(N=44)$ & $71.70(15.41)$ & \multicolumn{2}{|c|}{$11.66(6)$} \\
\hline Pediatric ward $(\mathrm{N}=22)$ & $67.77(14.11)$ & \multicolumn{2}{|c|}{$13.5(9)$} \\
\hline \multicolumn{4}{|c|}{$\begin{array}{l}\text { Table 4. Effect of Mental Workload Components on the Nurses' Mental Fatigue ( } N= \\
\text { 203) (Pearson Correlation Coefficient) }\end{array}$} \\
\hline \multirow{2}{*}{ Variables } & \multicolumn{3}{|c|}{ Mental Fatigue } \\
\hline & Mean \pm SD & $\mathbf{r}$ & PValue \\
\hline Mental fatigue & $13.24 \pm 7.21$ & - & - \\
\hline Mental demand & $61.67 \pm 25.36$ & 0.140 & 0.072 \\
\hline Physical demand & $62.35 \pm 27.22$ & 0.066 & 0.341 \\
\hline Temporal demand & $63.63 \pm 26.50$ & 0.042 & 0.540 \\
\hline Effort & $70.96 \pm 23.15$ & 0.047 & 0.501 \\
\hline Perceived performance & $59.86 \pm 25.35$ & 0.032 & 0.641 \\
\hline Frustration & $44.93 \pm 28$ & 0.000 & 0.279 \\
\hline Mental workload & $69.73 \pm 15.26$ & 0.080 & 0.12 \\
\hline
\end{tabular}

lationship between mental fatigue and workload, Pearson correlation coefficient showed no significant relationship between the two variables $(\mathrm{P}=0.12$; Table 4$)$.

\subsection{Correlation of Mental Fatigue with Contextual and Demo- graphic Factors}

Spearman correlation coefficient showed that mental fatigue is correlated with the number of shifts per month $(\mathrm{r}=0.171, \mathrm{P}=0.014)$. One-way ANOVA and independent $t$-test were used to examine the difference between nurses with different demographic and underlying characteristics in terms of mental fatigue. As shown in Table 4, nurses' mental fatigue and workload were not significantly different based on any of the demographic and underlying factors (P> 0.05; Table 5).

\subsection{Categories of Mental Fatigue}

Mental fatigue scores were classified in order to better understand its status among nurses. The findings showed that $20.7 \%$ of the nurses did not have any problems in terms of mental fatigue and $67 \%$ had minor problems (Table 6). ANOVA did not reflect any significant relationship between mental workload and different levels of mental fatigue including serious problems, relatively serious problems, minor problems and without problems $(\mathrm{P}=0.16)$. 


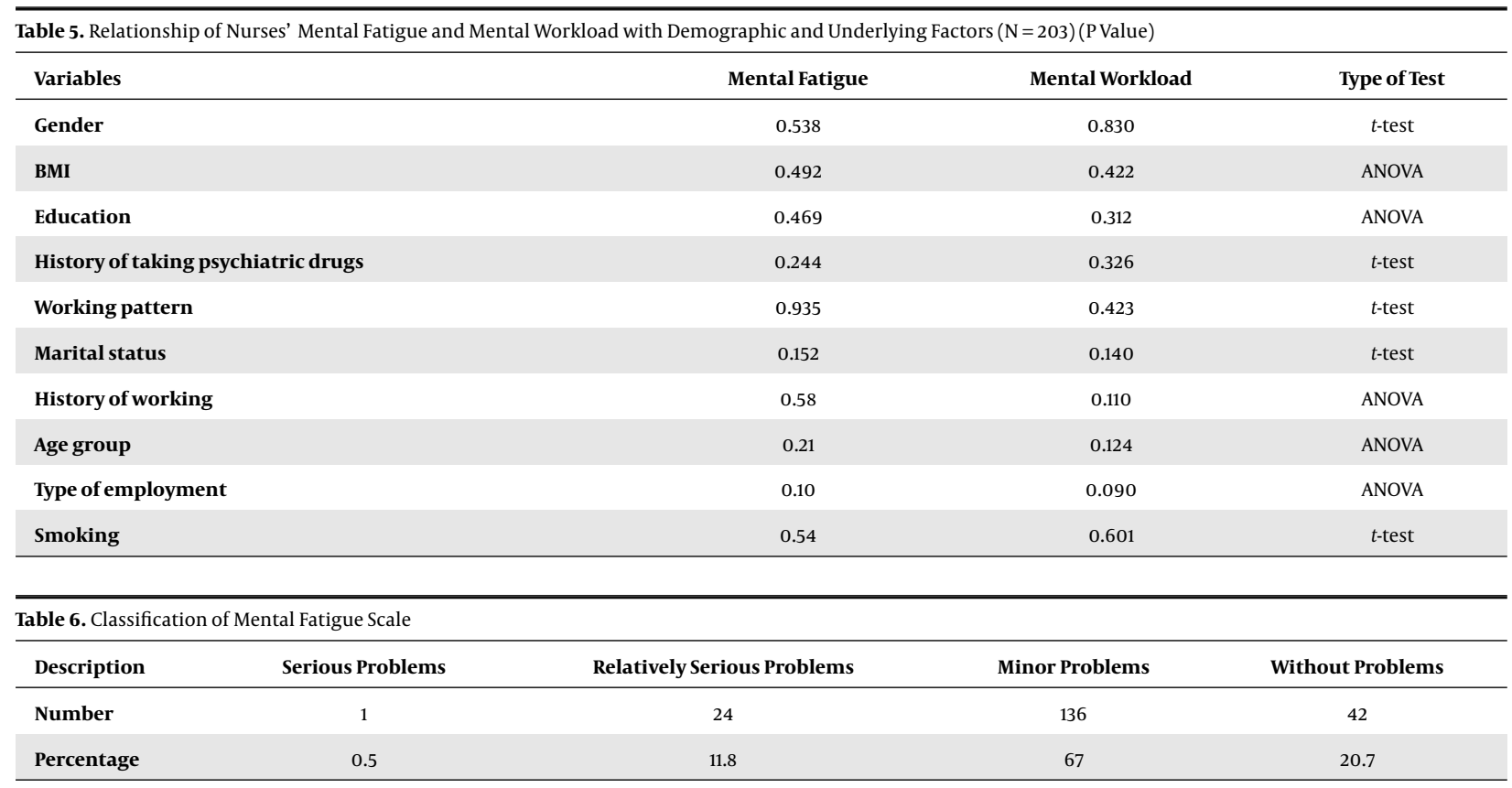

\section{Discussion}

The majority of the nurses experienced only minor mental fatigue during the past month. The reason for this could be the structure of the questionnaire, since the questionnaire was designed among the patients. In this study, mental workload was not recognized as an effective factor in different categories of mental fatigue. This can be accounted for the low score of mental fatigue since mental fatigue instrument evaluated the staff's mental fatigue within the past month and the evaluation of mental workload was accomplished solely during working shifts. Moreover, in this study, only the number of shifts per month had a significant relationship with mental fatigue and other demographic variables and underlying factors were not identified effective in mental fatigue.

Few studies were found concerning mental fatigue in nurses. In the research conducted by Kunert et al. (20), the severity of fatigue in nurses was less than the average amount, which is in line with the findings of the present study. In that study, a significant correlation was obtained between fatigue and sleep quality, thereby, the duration of sleep and sleep quality can be considered as effective factors that should receive attention.

Akerstedt et al. (21), proposed that disturbed sleep, high work demand, female gender, being a supervisor and advanced age are predictors of mental fatigue, whereas shift working and working hours (including overtime) were not significantly correlated with fatigue. They identified that disturbed sleep was mostly related to fatigue than workload. The overall result of mental fatigue in this study is consistent with the findings of Parhizi et al. (22) study conducted among nurses at the University of Missouri. The mean scores in both studies were smaller than the average score.

In this research, mental fatigue was not significantly correlated with mental workload; on the other hand, Fan and Smith (23), in their study declared that workload is one of several predictors of fatigue. Hassanzadeh-Rangi et al. (24) showed that mental workload is associated with all the dimensions of fatigue including mental and physical ones. Grech et al. (25) reported that the relationship between fatigue and workload is non-monotonic. Also, high and low workloads were associated with fatigue. No significant relationship was found between mental fatigue and mental workload in this study in comparison to the research conducted by Mirzaee et al. (26). However, Subramanyam et al. (27) indicated that excessive mental workload caused cognitive fatigue while in the current study, only $3.9 \%$ of the participants reported high mental workload. Generally, the differences in results could be due to the diversity of the assessment tools. As in this research, only the mental aspect of fatigue was investigated. Meanwhile, the questionnaire of mental fatigue in this research was designed among patients and evaluated the status of individual during the past month. Also, the evaluation tool of mental fatigue in the current study was more specialized and included more dimensions of mental fatigue than the instruments used in other studies. Therefore, the type of assessment tool may explain the differences in outcomes. 
In this study, the average number of shifts, as one of the influencing factors on mental fatigue, was equal to 13.9 times a month, which is relatively high. On the other hand, nurses need to be fully alert and maintain this alertness at all shift times to offer better patient care. Therefore, it can be argued that it is essential to pay attention to working pattern and reducing the number of shifts because it was also revealed in Kato et al.'s (28) study that reaction time increases with increasing the duration of tasks.

In a study conducted by Jones et al. (29), fatigue was correlated with such variables as gender, marital status, ratio of nurses to patients and working hours, while no correlation was observed between the demographic and underlying factors and mental fatigue in this study. This difference can be attributed to the time of evaluation. In fact, fatigue was evaluated at the present moment in Jones's research, while the individual's fatigue status was evaluated over the past month in the present study. On the other hand, fatigue in nurses was influenced by responsibilities outside the workplace, such as family tasks and parenting. In the present study, about $42 \%$ of the nurses were single, and thereby, their responsibility outside the hospital system was less compared to married nurses and they recovered from fatigue sooner $(11,29)$.

Kazemi et al. (14) carried out a study on locomotive drivers to assess the effect of mental workload on fatigue where the impact of workload on fatigue was significant only at the end of shifts. Indeed, there was no significant effect half an hour before movement. This somehow explains the findings of the present study as we evaluated the amount of nurses' mental fatigue during the past month.

In this study, the degree of workload among nurses was higher than the average level, which is consistent with the findings reported by Padilha et al. (30). Similar to Zheng et al.'s (31) study, the lowest score of workload was related to frustration level (44.84). Organizational factors and sufficient human resources were among the effective factors on workload and, according to the average nursing shifts, one can conclude that the number of nurses is required to increase to reduce workload (13). Shortage of human resources is among the factors contributing to high workload and burnout $(32,33)$. In a study undertaken by Smith (34), NASA-TLX was used to examine mental workload in computer users of a telecommunication company, and it was revealed that there is a direct relationship between the mental fatigue caused by long working hours and mental workload. Although nurses deal with less cognitive tasks than computer users, it is necessary to pay attention to the issues of workload and fatigue among nurses.

Excessive workload $(35,36)$, little opportunity for patient care (37) and the high ratio of patients to nurses have been introduced among the main reasons for reduced turnover and displacement among nurses (38)

High workload has been identified as one of the effective factors in stress (39), job dissatisfaction (40) and burnout (41). Workload is a multi-factorial variable in such a way that factors including nursing team, the type of wards and units and hospital can be effective in workload in addition to the factors pertaining to patient care. Therefore, authorities should be aware of the variety of factors affecting workload in nurses and provide some solutions to reduce nurses' workload (42).

\subsection{Conclusions}

The overall results of this study showed that most of the nurses were in a relatively desirable state regarding mental fatigue; however, nurses' workload was high. Since high workload can lead to the incidence of work-related accidents, measures should be taken to decrease the degree of workload. Increased number of nurses and their displacement among various departments and wards can be effective in reducing their workload and mental fatigue. In this study, demographic and underlying factors were not recognized to cause mental fatigue; hence, future studies in this area are recommended. Questionnaire-based studies for assessing nurses using objective methods are also essential for reaching better results.

\section{Acknowledgments}

This article is the result of a Master's thesis submitted to Tehran University of Medical Sciences in the field of ergonomics with the Secretariat No. of 240/1586. The authors sincerely express their gratitude to the staff of Imam Reza Hospital at Kermanshah and the nurses participating in this project.

\section{Footnotes}

Conflict of Interests: The authors declare no conflict of interests.

Ethical Considerations: This article is the result of a Master's thesis submitted to Tehran University of Medical Sciences in the field of ergonomics with the Secretariat No. of 240/1586.

Funding/Support: This study was conducted without financial support.

\section{References}

1. Salehi K, Alhani F, Mahmoudifar Y, Rouhi N. [Quality of sleep and related factors among Imam Khomeini hospital staff nurses]. Iran J Nurs. 2010;23(63):18-25. Persian. 
2. Li A, Early SF, Mahrer NE, Klaristenfeld JL, Gold JI. Group cohesion and organizational commitment: Protective factors for nurse residents' job satisfaction, compassion fatigue, compassion satisfaction, and burnout. I Prof Nurs. 2014;30(1):89-99. doi: 10.1016/j.profnurs.2013.04.004. [PubMed: 24503320].

3. Berry L, Curry P. Nursing workload and patient care: Understanding the value of nurses, the effects of excessive workload, and how nurse-patient ratios and dynamic staffing models can help. Canadian Federation of Nurses Unions; 2013.

4. Raftopoulos V, Charalambous A, Talias M. The factors associated with the burnout syndrome and fatigue in Cypriot nurses: A census report. BMC Public Health. 2012;12:457. doi: 10.1186/1471-2458-12-457. [PubMed: 22716044]. [PubMed Central: PMC3506490].

5. Qu S. An investigation of the influence of pediatric unit design on nurses' fatigue [dissertation]. The University of North Carolina at Greensboro; 2014.

6. Shen KQ, Li XP, Ong CJ, Shao SY, Wilder-Smith EP. EEG-based mental fatigue measurement using multi-class support vector machines with confidence estimate. Clin Neurophysiol. 2008;119(7):1524-33. doi: 10.1016/j.clinph.2008.03.012. [PubMed: 18468483].

7. Marcora SM, Staiano W, Manning V. Mental fatigue impairs physical performance in humans. JAppl Physiol (1985). 2009;106(3):857-64. doi: 10.1152/japplphysiol.91324.2008. [PubMed: 19131473].

8. Muecke S. Effects of rotating night shifts: Literature review. J Adv Nurs. 2005;50(4):433-9. doi: 10.1111/j.1365-2648.2005.03409.x. [PubMed: 15842451].

9. Lorist MM, Klein M, Nieuwenhuis S, De Jong R, Mulder G, Meijman TF. Mental fatigue and task control: Planning and preparation. Psychophysiology. 2000;37(5):614-25. [PubMed: 11037038].

10. Dashti E, Rassouli M, Mojen Khanali L, Hoseingholi Pour A, Farahani Shirinabady A, Sarvi F. [Nurses'fatigue in neonatal intensive care units and premature infants'readmissions]. Iran J Nurs Res. 2015;10(2):1-10. Persian.

11. Hazzard B, Johnson K, Dordunoo D, Klein T, Russell B, Walkowiak P. Work- and nonwork-related factors associated with PACU nurses' fatigue. J Perianesth Nurs. 2013;28(4):201-9. doi: 10.1016/j.jopan.2012.06.010. [PubMed: 23886284].

12. Young G, Zavelina L, Hooper V. Assessment of workload using NASA task load index in perianesthesia nursing. $J$ Perianesth Nurs. 2008;23(2):102-10. doi: 10.1016/j.jopan.2008.01.008. [PubMed: 18362006].

13. Myny D, Van Hecke A, De Bacquer D, Verhaeghe S, Gobert M, Defloor $\mathrm{T}$, et al. Determining a set of measurable and relevant factors affecting nursing workload in the acute care hospital setting: A cross-sectional study. Int J Nurs Stud. 2012;49(4):427-36. doi: 10.1016/j.ijnurstu.2011.10.005. [PubMed: 22030021].

14. Kazemi Z, Mazloumi A, Saraji G, Hosseini M. [Investigating workload and its relationship with fatigue among train drivers in Keshesh section of Iranian Railway Company].J Health SafWork. 2012;2(3):1-8. Persian.

15. Jansen NW, van Amelsvoort LG, Kristensen TS, van den Brandt PA, Kant IJ. Work schedules and fatigue: A prospective cohort study. Occup Environ Med. 2003;60 Suppl 1:i47-53. [PubMed: 12782747]. [PubMed Central: PMC1765732]

16. Kiekkas P, Sakellaropoulos GC, Brokalaki H, Manolis E, Samios A, Skartsani C, et al. Association between nursing workload and mortality of intensive care unit patients. J Nurs Scholarsh. 2008;40(4):385-90. doi: 10.1111/j.1547-5069.2008.00254.x. [PubMed: 19094155].

17. Conishi RMY, Gaidzinski RR. Nursing activities score (NAS) como instrumento para medir carga de trabalho de enfermagem em UTI adulto. Revista da Escola de Enfermagem da USP. 2007;41(3):346-54. doi: 10.1590/s0080-62342007000300002.

18. Mohammadi M, Mazloumi A, Zeraati H. [Designing questionnaire of assessing mental workload and determine its validity and reliability among ICUs nurses in one of the TUMS's hospitals].J Sch Public Health Institute Public Health Res. 2013;11(2):87-96. Persian.
19. Johansson B, Starmark A, Berglund P, Rodholm M, Ronnback L. A selfassessment questionnaire for mental fatigue and related symptoms after neurological disorders and injuries. Brain Inj. 2010;24(1):2-12. doi: 10.3109/02699050903452961. [PubMed: 20001478].

20. Kunert K, King ML, Kolkhorst FW. Fatigue and sleep quality in nurses.J Psychosoc Nurs Ment Health Serv. 2007;45(8):30-7. [PubMed: 17848042].

21. Akerstedt $\mathrm{T}$, Knutsson A, Westerholm P, Theorell $\mathrm{T}$, Alfredsson L, Kecklund G. Mental fatigue, work and sleep. J Psychosom Res. 2004;57(5):427-33. doi: 10.1016/j.jpsychores.2003.12.001. [PubMed: 15581645].

22. Parhizi S, Steege LM, Pasupathy KS. [Mining the relationships between psychosocial factors and fatigue dimensions among registered nurses]. Int J Ind Ergonom. 2013;43(1):82-90. Persian. doi: 10.1016/j.ergon.2012.11.010.

23. Fan J, Smith AP. The impact of workload and fatigue on performance. In: Longo L, Chiara Leva M, editors. International symposium on human mental workload: Models and applications. 726. Springer, Cham; 2017. p. 90-105.

24. Hassanzadeh-Rangi N, Khosravi Y, Sarami M, Jafari MJ. [Mental workload and its relation with fatigue among urban bus drivers]. J Occup Hygiene Engin. 2017;4(1):66-73. Persian. doi: 10.21859/johe-04018.

25. Grech MR, Neal A, Yeo G, Smith S, Humphreys M. An examination of the relationship between workload and fatigue within and across consecutive days of work: Is the relationship static or dynamic? J Occup Health Psychol. 2009;14(3):231-42. doi: 10.1037/a0014952. [PubMed: 19586219].

26. Zamanian Z, Zade JH. Effects of work shifts and mental workload on chronic fatigue among female nurses in intensive care units.J Health Sci Surveillance Sys. 2015;3(3):113-8.

27. Subramanyam M, Muralidhara P, Pooja M. Mental workload and cognitive fatigue: A study. IUP J Manag Res. 2013;12(2):29.

28. Kato $\mathrm{Y}$, Endo $\mathrm{H}$, Kizuka T. Mental fatigue and impaired response processes: Event-related brain potentials in a Go/NoGo task. Int J Psychophysiol. 2009;72(2):204-11. doi: 10.1016/j.ijpsycho.2008.12.008. [PubMed: 19135100].

29. Jones G, Hocine M, Salomon J, Dab W, Temime L. Demographic and occupational predictors of stress and fatigue in French intensive-care registered nurses and nurses' aides: A cross-sectional study. Int J Nurs Stud. 2015;52(1):250-9. doi: 10.1016/j.ijnurstu.2014.07.015. [PubMed: 25443305].

30. Padilha KG, de Sousa RM, Garcia PC, Bento ST, Finardi EM, Hatarashi RH. Nursing workload and staff allocation in an intensive care unit: A pilot study according to nursing activities score (NAS). Intensive Crit Care Nurs. 2010;26(2):108-13. doi: 10.1016/j.iccn.2009.12.002. [PubMed: 20060720].

31. Zheng B, Jiang X, Tien G, Meneghetti A, Panton ON, Atkins MS. Workload assessment of surgeons: correlation between NASA TLX and blinks. Surg Endosc. 2012;26(10):2746-50. doi: 10.1007/s00464-0122268-6. [PubMed: 22527300].

32. Bragard I, Dupuis G, Fleet R. Quality of work life, burnout, and stress in emergency department physicians: A qualitative review. Eur J Emerg Med. 2015;22(4):227-34. doi: 10.1097/MEJ.0000000000000194. [PubMed: 25093897].

33. Al-Kandari F, Thomas D. Adverse nurse outcomes: Correlation to nurses' workload, staffing, and shift rotation in Kuwaiti hospitals. Appl Nurs Res. 2008;21(3):139-46. doi: 10.1016/j.apnr.2006.10.008. [PubMed: 18684407].

34. Smith BK. Test your stamina for workplace fatigue. Can you recognize the warning signs? Nurs Manage. 2004;35(10):38-40. [PubMed: 15638450].

35. Cline D, Reilly C, Moore JF. What's behind RN turnover? Nurs Manage. 2003;34(10):50-3. [PubMed: 14557783].

36. Sjogren K, Fochsen G, Josephson M, Lagerstrom M. Reasons for leaving nursing care and improvements needed for considering a return: A study among Swedish nursing personnel. Int J Nurs 
Stud. 2005;42(7):751-8. doi: 10.1016/j.ijnurstu.2004.11.001. [PubMed: 16084923].

37. Fottler MD, Widra LS. Intention of inactive registered nurses to return to nursing. Med Care Res Rev. 1995;52(4):492-516. doi: 10.1177/107755879505200404. [PubMed: 10153311].

38. Chan EY, Morrison P. Factors influencing the retention and turnover intentions of registered nurses in a Singapore hospital. Nurs Health Sci. 2000;2(2):113-21. doi: 10.1046/j.1442-2018.2000.00046.x.

39. Hillhouse JJ, Adler CM. Investigating stress effect patterns in hospital staff nurses: Results of a cluster analysis. Soc Sci Med.1997;45(12):17818. [PubMed: 9447628].
40. Sheward L, Hunt J, Hagen S, Macleod M, Ball J. The relationship between UK hospital nurse staffing and emotional exhaustion and job dissatisfaction. J Nurs Manag. 2005;13(1):51-60. doi: 10.1111/j.13652834.2004.00460.x. [PubMed: 15613094].

41. Spooner-Lane R, Patton W. Determinants of burnout among public hospital nurses. Aust J Adv Nurs. 2007;25(1):8.

42. Myny D, Van Goubergen D, Gobert M, Vanderwee K, Van Hecke A, Defloor T. Non-direct patient care factors influencing nursing workload: A review of the literature. J Adv Nurs. 2011;67(10):2109-29. doi: 10.1111/j.1365-2648.2011.05689.x. [PubMed: 21722164]. 